\title{
Filthy Animals: Integrating the Behavioral Immune System and Disgust into a Model of Prophylactic Dehumanization
}

\author{
Alexander P. Landry ${ }^{1}$ [ $\cdot$ Elliott $\mathrm{Ihm}^{1}$. Jonathan W. Schooler ${ }^{1}$
}

Received: 1 July 2021 / Revised: 30 July 2021 / Accepted: 25 August 2021

(c) The Author(s), under exclusive licence to Springer Nature Switzerland AG 2021

\begin{abstract}
The behavioral immune system (BIS) is an evolved psychological mechanism that motivates prophylactic avoidance of disease vectors by eliciting disgust. When felt toward social groups, disgust can dampen empathy and promote dehumanization. Therefore, we investigated whether the BIS facilitates the dehumanization of groups associated with disease by inspiring disgust toward them. An initial content analysis found that Nazi propaganda predominantly dehumanized Jews by portraying them as disease vectors or contaminants. This inspired three correlational studies supporting a Prophylactic Dehumanization Model in which the BIS predicted disgust toward disease-relevant outgroups, and this disgust in turn accounted for the dehumanization of these groups. In a final study, we found this process of prophylactic dehumanization had a downstream effect on increasing anti-immigrant attitudes during the COVID-19 pandemic. However, consistent with the evolutionary logic of a functionally flexible BIS, this effect only occurred when the threat of COVID-19 was salient. The implications of these results for the study of dehumanization and evolutionary theories of xenophobia are discussed.
\end{abstract}

Keywords Dehumanization $\cdot$ Behavioral immune system $\cdot$ Disgust $\cdot$ COVID-19 $\cdot$ Immigration $\cdot$ Prophylactic Dehumanization Model

\section{Introduction}

Just as the body developed a physiological immune system, our minds have developed a behavioral immune system (BIS), psychological mechanisms that motivate behaviors to avoid infection (Schaller, 2015). The BIS is predicated on disgust, which inspires prophylactic withdrawal from fitness-compromising disease threats (Curtis et al., 2011, 2004). Along with reacting to physical contaminants such as vomit or bodily fluids (Curtis et al., 2004), a growing body of evidence suggests that the BIS also motivates disgust and withdrawal from certain social groups (e.g., Aarøe et al., 2017; Brown et al., 2019; Faulkner et al., 2004). BIS-inspired disgust toward outgroups may have evolved because outgroups harbored novel pathogens that could be particularly virulent if introduced into one's ingroup (e.g., the decimation of certain Native American populations upon contact with European colonizers; Diamond, 1997).

Alexander P. Landry

alandry@stanford.edu

1 Department of Psychological and Bran Sciences, University of California, Santa Barbara, CA, USA
Alternatively, outgroup members may have posed a disease threat by violating ingroup norms that defend against contagion (e.g., food preparation practices, sexual or hygienic taboos; Schaller, 2015).

Importantly, outgroups do not need to pose an actual disease threat for the BIS to inspire disgust toward them. The dire consequences of contracting a debilitating disease imposed selective pressures on the BIS that biased it to be hypersensitive to disease cues, raising many "false alarms" to stimuli that are not actually infectious (Schaller, 2015). For instance, people with benign facial disfigurements elicit the same disgust response as those with infectious diseases, even when participants are told the disfigurement is merely a superficial birthmark (Ryan et al., 2012; Schaller \& Duncan, 2007). The hypersensitivity of the BIS may explain why a wide variety of outgroups can elicit disgust (i.e., intergroup disgust; Hodson et al., 2013), not only targets with deviant physical appearances, but also those with a subjectively foreign religion or ethnicity (e.g., Choma et al., 2016) and those perceived to violate traditional social norms (e.g., Terrizzi et al., 2010). 
Between- and within-individual variation in BIS sensitivity Although there are benefits to being hypervigilant to cues of infection, prophylactic avoidance can also be costly (e.g., forgoing an opportunity to establish a beneficial social relationship). In response to different cost-benefit tradeoffs, individuals establish reliably different sensitivities toward potential disease threats (Aarøe et al., 2017). Just as some are more agreeable or extraverted, some are more sensitive to disease threats (Duncan et al., 2009). Moreover, an individual's BIS sensitivity is not static, but dynamically adjusts to environmental cues. All else being equal, the BIS has a greater influence on affect and behavior in situations where pathogen threats are salient (Schaller, 2015). For instance, when their physiological immune system is suppressed during the first months of pregnancy, women's BIS sensitivity is heightened (Navarrete et al., 2007). This "functional flexibility" has direct implications for intergroup relations: the association between an individual's BIS sensitivity and their aversion toward outgroups is amplified when pathogens are salient (e.g., Faulkner et al., 2004).

BIS sensitivity and intergroup disgust Disgust is a reliable marker of the BIS, and the intensity with which individuals experience disgust in the presence of disease cues is often used to index their BIS sensitivity (e.g., Aarøe et al., 2017). There are important distinctions between the two, however. The BIS is a distal psychological mechanism that motivates a proximal disgust response to potential disease threats, and this proximal experience of disgust is an independent and generally stronger predictor of behavior toward the potential disease threat. For instance, although individuals' BIS sensitivity generally predicts aversive attitudes and behavior toward outgroups (i.e., xenophobia), this relationship is wholly explained by their experience of intergroup disgust (Choma et al., 2012; Hodson et al., 2013). In fact, traditional measures of BIS sensitivity and intergroup disgust are only moderately correlated ( $r=0.33$; Hodson et al., 2013).

\section{The Prophylactic Dehumanization Model}

Although the BIS has been found to inspire general negativity toward outgroups (e.g., Aarøe et al., 2017), no work to our knowledge has directly investigated its effect on dehumanization, or the process of conceiving of another person as less than fully human. This is a critical gap because dehumanization facilitates aggression by disengaging the moral considerations typically preventing harm to fellow human beings (Bandura, 1999; Bandura et al., 1975). ${ }^{1}$ This

\footnotetext{
${ }^{1}$ Recent work, perhaps most notably by Rai et al. (2017) and Over (2021), has challenged these longstanding assumptions about dehumanization's role in violence. However, these critiques may have
}

explains why individuals who dehumanize an outgroup also support discrimination, military belligerence, and using torture against them (Kteily et al., 2015; Maoz \& McCauley, 2008; Viki et al., 2013). Despite a burgeoning body of work documenting dehumanization's corrosive impact on intergroup relations (see Kteily \& Bruneau, 2017 for an overview), insight into the psychological mechanisms underlying it remain limited.

One such underlying mechanism may be the BIS-inspired disgust toward particular outgroups. This is because disgust dampens the empathy and mentalizing necessary to recognize another's full humanity (Hodson et al., 2014; Sherman \& Haidt, 2011), leading individuals to implicitly associate outgroup members with non-human animals (Buckels \& Trapnell, 2013; Skinner \& Hudac, 2017) and promoting the dehumanization of norm violators (Giner-Sorolla et al., 2019; see also Dalsklev \& Kunst, 2015). Moreover, groups that are stigmatized due to their perceived lack of warmth and competence both elicit disgust and are considered less capable of complex, "uniquely human" experiences (Harris \& Fiske, 2011). Outside of the laboratory, perpetrators of violence often liken their victims to infectious diseases or their vectors such as rats and cockroaches (Musolff, 2007; Smith, 2020), and this disease-based dehumanization is thought to facilitate genocidal violence due to the prophylactic disgust it inspires (Neilsen, 2015; Savage, 2007).

Nonetheless, empirical research linking disgust to dehumanization has largely focused on relatively subtle forms of dehumanization, such as the denial of uniquely human traits, that is a far cry from the blatant dehumanization thought to foment intergroup violence (see Kteily \& Bruneau, 2017 for review). Therefore, we move beyond previous work by considering whether disgust also facilitates the blatant dehumanization consistently predictive of support for intergroup violence (Kteily \& Bruneau, 2017). Moreover, we ground our account in evolutionary theory by considering whether disgust's effect on dehumanization is itself rooted in evolved disease-avoidance mechanisms. Namely, we sought support for a Prophylactic Dehumanization Model in which individuals' BIS sensitivity leads them to feel disgust toward disease-relevant outgroups, ${ }^{2}$ and this disgust in turn leads them to dehumanize these groups (Fig. 1).

\footnotetext{
Footnote 1 (continued)

arrived at their conclusions based on operationalizations of dehumanization that fail to capture the breadth of the construct (Fincher et al., 2018).

2 By "disease-relevant" we mean outgroups with qualities probabilistically associated with disease cues in ancestral environments. However, as mentioned above, due to the hypersensitivity of the BIS such outgroups need not pose any actual disease threat to elicit disgust.
} 


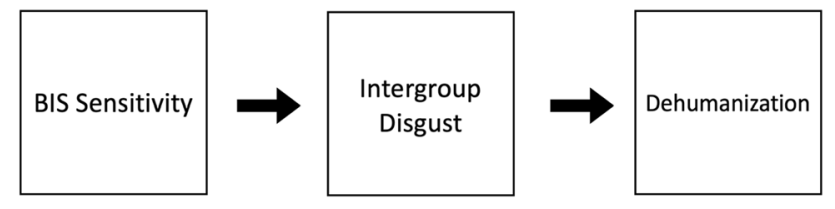

Fig. 1 The Prophylactic Dehumanization Model

Covariates In testing this model, we took into account other personality traits and attitudes that could explain any effects of BIS sensitivity and disgust on dehumanization. Since feeling disgust toward outgroups can reinforce existing status hierarchies (Hodson et al., 2013; Rozin et al., 2008), it may be particularly prominent among those who generally desire to maintain existing social hierarchies (i.e., social conservatives) and those who support group-based hierarchies in general (i.e., high social dominance orientation, or SDO; Pratto et al., 1994). Since conservatives and those high in SDO are both more likely to dehumanize low-status outgroups (Hodson \& Costello, 2007; Kteily et al., 2015), we account for these individual differences when testing our model. Moreover, to determine whether our inclusion of dehumanization in this model may just reflect general negativity toward the outgroup (Enock et al., 2021), we also accounted for participants' affective prejudice toward each group.

\section{The Present Research}

The Prophylactic Dehumanization Model suggests that the BIS facilitates dehumanization by inspiring disgust toward disease-relevant outgroups. This may explain why dehumanization likening victims to diseases or their vectors (e.g., rats and cockroaches) is thought to have played an integral role in several twentieth-century genocides (Neilsen, 2015; Savage, 2007). To quantify the prevalence of disease-based dehumanization during a paradigmatic instance of genocide, we first re-analyzed data from a previous content analysis of Nazi antisemitic propaganda (Enock et al., 2020). We then built on this archival method with three studies investigating the Prophylactic Dehumanization Model during the COVID19 pandemic.

Study 1 tested whether Americans' BIS sensitivity predicted their disgust toward Chinese people, a group frequently associated with the pandemic (Darling-Hammond et al., 2020), and whether disgust in turn predicted the dehumanization of Chinese people (Fig. 1). To determine the robustness of our model, we next examined whether this process of prophylactic dehumanization generalized to 10 additional disease-relevant outgroups (studies $2 \mathrm{a}$ and $2 b$ ). Finally, we tested the functional flexibility principle of the BIS by determining whether the Prophylactic
Dehumanization Model was moderated by the salience of COVID-19. We also examined whether this process of prophylactic dehumanization fomented Americans' antiimmigrant attitudes (Study 3).

\section{Re-Analysis of Nazi Propaganda}

The Holocaust serves as a paradigmatic instance in which victims were likened to infectious diseases or contaminants (Musolff, 2007; Neilsen, 2015; Savage, 2007), leading us to conduct a preliminary content analysis to quantify the prevalence of this form of disease-based dehumanization in Nazi propaganda. Our data come from Florence Enock and colleagues (2020), who initially analyzed ten antisemitic Nazi propaganda documents published between 1936 and 1944, available on the German Propaganda Archive (https:// research.calvin.edu/german-propaganda-archive/). The documents consist of flyers, pamphlets, books, and material for political speeches intended for a variety of audiences, including young children, the general public, and members of the Nazi party. The documents were all translated to English by the same expert historian (see Bytwerk, 2012) and amount to 29,185 total words. A brief synopsis of each document provided by Enock et al. (2020) is included in Online Resource 1.

Enock et al. (2020) initially coded each document for instances of dehumanization, identifying 171 total instances. We examined each of these 171 cases and identified those in which Jews were dehumanized in a way that directly likened them to a contaminant (e.g., plague, pestilence) or a common vector of disease (e.g., parasite, rat). Jews were subject to this disease-based dehumanization in 105 of the 171 cases $(61.4 \%)$. The most prevalent term for disease-based dehumanization was parasite $(n=54)$. Other common terms were poison/poisonous $(n=21)$ and plague $(n=12)$. The frequencies for all the disease-based dehumanization terms are presented in Table $\mathrm{S} 1$ of Online Resource $1 .^{3}$

Enock et al. (2020) did not intend these 10 documents to be considered representative of Nazi propaganda in any way, so we refrain from making any generalizations on their basis. Moreover, even if these results suggest that disease-based dehumanization was a prevalent form of dehumanization during the Nazi regime, they do not provide insight into the underlying mechanism thought to give such genocidal rhetoric its potency: disgust (Savage, 2007; Wasniewska,

\footnotetext{
${ }^{3}$ Enock et al.'s (2020) full coded Word documents along with an Excel file detailing their results can be found at https://osf.io/ca38j/, while our results can also be accessed in an Excel file (titled "Enock et al., 2020 Content Analysis") at https://osf.io/5387z/?view_only= 61074e103b2e461e958d62f061193e78.
} 
2017). ${ }^{4}$ Nonetheless, this archival investigation accords with qualitative research implicating disease-based dehumanization in genocide (Neilsen, 2015; Savage, 2007) and provided an impetus to directly test our model of prophylactic dehumanization.

\section{Study 1}

As COVID-19 spread from China in February-March 2020, Chinese people faced intense discrimination due to fear about the virus (Darling-Hammond et al., 2020; Ren et al., 2020; Zhai \& Du, 2020). In the USA, influential politicians and media outlets implicated China in the pandemic, and Chinese-Americans were verbally abused and physically attacked (Tavernese \& Oppel Jr., 2020). In fact, some even blatantly dehumanized Chinese people (Markowitz et al., 2021). Therefore, beginning the day President Trump announced the pandemic was a national public health crisis (March 13, 2020; AMJC, 2020), we tested the Prophylactic Dehumanization Model among a sample of Americans. We expected Americans' BIS sensitivity to predict disgust toward Chinese people, which in turn would predict greater dehumanization of them (Fig. 1). This was expected to occur over and above participants' social dominance orientation, social conservatism, and prejudice toward Chinese people.

\section{Method}

\section{Participants}

We conservatively estimated a small-to-medium effect on the basis of past research $\left(f^{2}=0.1\right.$; Kteily et al., 2015) but initially recruited 740 participants to maximize power. We excluded 89 who either were Chinese(-American) or failed an attention check item, leaving us with a final sample of 651 (age: $M=37.45, S D=12.97 ; 304$ male, 345 female, 2 other). We used a tool for Monte Carlo post hoc power analysis developed by Schoemann et al. (2017) to determine we had power of 1.00 to detect the indirect effect we observed.

\section{Materials}

BIS Sensitivity BIS sensitivity was assessed with the 15-item Perceived Vulnerability to Disease scale (PVD;

\footnotetext{
${ }^{4}$ Enock et al. (2020) considered the low base rate of dehumanization in these documents ( 171 out of $>29,000$ words) to suggest that it may not have been as prevalent in the Nazi Holocaust as is frequently assumed. While we were interested in identifying the proportion of dehumanization that took a particular form, rather than absolute levels of dehumanization, this is an important consideration that is also taken up by Johannes Lang (2010; see also Luft, 2019).
}

Duncan et al., 2009; $a=0.82)$. It consists of a perceived infectability subscale measuring beliefs about one's susceptibility to infection (If an illness is 'going around', I will get $i t ; a=0.84)$, and a germ aversion subscale measuring discomfort in situations with the potential for pathogen transmission (I do not like to write with a pencil someone else has obviously chewed on; $a=0.65)$. Participants responded on a Likert scale ranging from 1 (Strongly disagree) to 7 (Strongly agree).

Intergroup Disgust Intergroup disgust was measured with the scale developed by Hodson et al. $(a=0.85 ; 2013) .{ }^{5}$ Participants rated their agreement with 8 items reflecting their disgust toward Chinese people (e.g., I would feel disgusted if a Chinese person invaded my personal space) using a Likert scale ranging from 1 (Strongly disagree) to 7 (Strongly agree).

Dehumanization This measure of blatant dehumanization presented participants with the popular "Ascent of Man" image depicting the folk theory of human evolution ranging from a quadrupedal primate ancestor to a fully modern man (Kteily et al., 2015). Participants rated the target with a slider scale that ranged from 0 (Least Evolved) to 100 (Most Evolved). Scores were reversed such that higher scores indicated greater dehumanization.

General Prejudice Prejudice was measured using the feeling thermometer (Haddock et al., 1993), which asked participants to evaluate a typical outgroup member on a slider scale ranging from 0 (Extremely Unfavorable) and 100 (Extremely Favorable). Scores were reversed such that higher scores indicated greater prejudice.

Social Dominance Orientation We measured SDO with the 8-item $\mathrm{SDO}_{7(\mathrm{~S})}$ scale (Ho et al., 2015; $\alpha=0.89$ ), which assesses support for group-based dominance (e.g., An ideal society requires some groups to be on top and others to be on the bottom) and anti-egalitarianism (e.g., It is unjust to try to make groups equal). Participants responded using a scale ranging from 1 (Strongly Oppose) to 7 (Strongly Favor).

\footnotetext{
${ }^{5}$ Hodson et al. identified intergroup disgust “.... as an overlooked contributor to negative outgroup attitudes, both as individual difference and as an induced state" (2013; p. 196). They focused on developing a measure of individual differences in the general proclivity to experience intergroup disgust, rather than the acute disgust induced by a particular outgroup. We focus on the latter phenomenon, measuring intergroup disgust toward each particular outgroup rather than as a stable individual difference, although it would be worthwhile for future research to investigate whether individual differences in trait intergroup disgust explain unique variance in dehumanization like other individual differences such as SDO (Kteily et al., 2015).
} 
Table 1 Study 1 descriptive statistics and intercorrelations

\begin{tabular}{|c|c|c|c|c|c|c|c|}
\hline \multicolumn{2}{|l|}{ Correlations } & 1 & 2 & 3 & 4 & 5 & 6 \\
\hline \multicolumn{2}{|c|}{ 1. BIS sensitivity } & - & & & & & \\
\hline \multicolumn{2}{|c|}{ 2. Intergroup disgust } & $.19 * * *$ & - & & & & \\
\hline \multicolumn{2}{|c|}{ 3. Dehumanization (Chinese) } & .06 & $.46^{* * *}$ & - & & & \\
\hline \multicolumn{2}{|c|}{ 4. Dehumanization (ingroup) } & .07 & $.09 *$ & $.55^{* * *}$ & - & & \\
\hline \multicolumn{2}{|l|}{ 5. Prejudice } & .07 & $.40 * * *$ & $.54 * * *$ & $.19 * * *$ & - & \\
\hline \multicolumn{2}{|l|}{ 6. SDO } & -.05 & $.49 * * *$ & $.30 * * *$ & .02 & $.24 * * *$ & - \\
\hline \multicolumn{2}{|c|}{ 7. Social conservatism } & -.04 & $.37 * * *$ & $.15^{* * *}$ & -.05 & $.09^{*}$ & $.59 * * *$ \\
\hline Descriptives & 1 & 2 & 3 & 4 & 5 & 6 & 7 \\
\hline$M$ & 4.17 & 2.54 & 15.19 & 13.61 & 28.09 & 2.58 & 44.00 \\
\hline$S D$ & 0.85 & 1.27 & 19.39 & 18.85 & 22.80 & 1.39 & 29.62 \\
\hline$\alpha$ & .82 & .85 & - & - & - & .92 & - \\
\hline
\end{tabular}

*** $p<.001, * * p<.01, * p<.05$

Social Conservatism Social conservatism was measured by asking participants to Please indicate the extent to which you consider yourself to be liberal or conservative on most social issues (e.g., abortion, religion) on a slider scale ranging from 0 (Extremely Liberal) to 100 (Extremely Conservative).

\section{Procedure}

After providing consent, participants completed the PVD measure as an index of their BIS sensitivity and rated their disgust toward Chinese people. Next, they completed the Ascent scale of dehumanization and feeling thermometer of prejudice. On both these measures, they evaluated Chinese people and their ingroup (Americans), along with four filler groups, presented in randomized order. Participants then completed measures of SDO and conservatism, and provided demographics.

\section{Results and Discussion}

To test the Prophylactic Dehumanization Model, we conducted a simple mediation using the PROCESS macro for SPSS (Model 4; Hayes, 2018). ${ }^{6}$ In the model, Americans' BIS sensitivity was the predictor, disgust toward Chinese people was the mediator, and dehumanization of them was the outcome variable. SDO, social conservatism, and general prejudice toward Chinese people were entered as covariates. We also controlled for dehumanization of the ingroup (Americans) to account for measurement variance (see Landry et al., 2021 for precedent). Descriptive statistics and intercorrelations among these variables are presented

\footnotetext{
${ }_{6}$ All analyses using PROCESS were conducted with 5000 bootstrap resamples.
}

in Table 1, and a path diagram for the model is depicted in Fig. 2.

Observing the $a$ path of the mediation model, Americans' BIS sensitivity exerted a strong direct effect on their disgust toward Chinese people, $\beta=0.19, S E=0.05, t=5.99$, $p<0.001$. Disgust, in turn, exerted a strong effect on dehumanization ( $b$ path), $\beta=0.27, S E=0.50, t=8.08, p<0.001$. Finally, BIS sensitivity exerted an indirect effect on dehumanization, mediated by disgust, $\beta_{\text {indirect }}=0.05, S E=0.01$, $95 \%$ CI [0.03, 0.07]. Moreover, when disgust was taken into account, BIS sensitivity no longer exerted a significant effect on dehumanization, $\beta=-0.05, S E=0.61, t=-1.90$, $p=0.058$, suggesting full mediation. ${ }^{7}$

In sum, we found support for a model in which Americans' BIS sensitivity inspired disgust toward Chinese people during a time when they were frequently associated with disease by influential politicians and media outlets (e.g., Tavernese \& Oppel Jr., 2020). Disgust toward Chinese people, in turn, predicted greater blatant dehumanization of them. Understanding the factors shaping such blatant dehumanization may be paramount to addressing the discrimination and violence faced by Chinese people and other Asians in the USA during the COVID-19 pandemic (Croucher et al., 2020; Tavernese \& Oppel Jr., 2020; see also Markowitz et al., 2021). However, for the purposes of establishing a generalizable model of prophylactic dehumanization, our focus on this single population can be seen as a limitation. Therefore, to determine the generality of the Prophylactic Dehumanization Model, we broadened our investigation to consider a wider array of disease-relevant outgroups.

\footnotetext{
${ }^{7}$ Reversing the position of disgust and dehumanization in the model reduced the indirect effect to non-significance, suggesting the plausibility of the current model.
} 
Fig. 2 Effect of behavioral immune system (BIS) sensitivity on dehumanization of Chinese people, mediated by disgust. SDO, social conservatism, prejudice toward Chinese people, and dehumanization of ingroup (Americans) were entered as covariates. Values reflect standardized coefficients. $* * * p<.001$

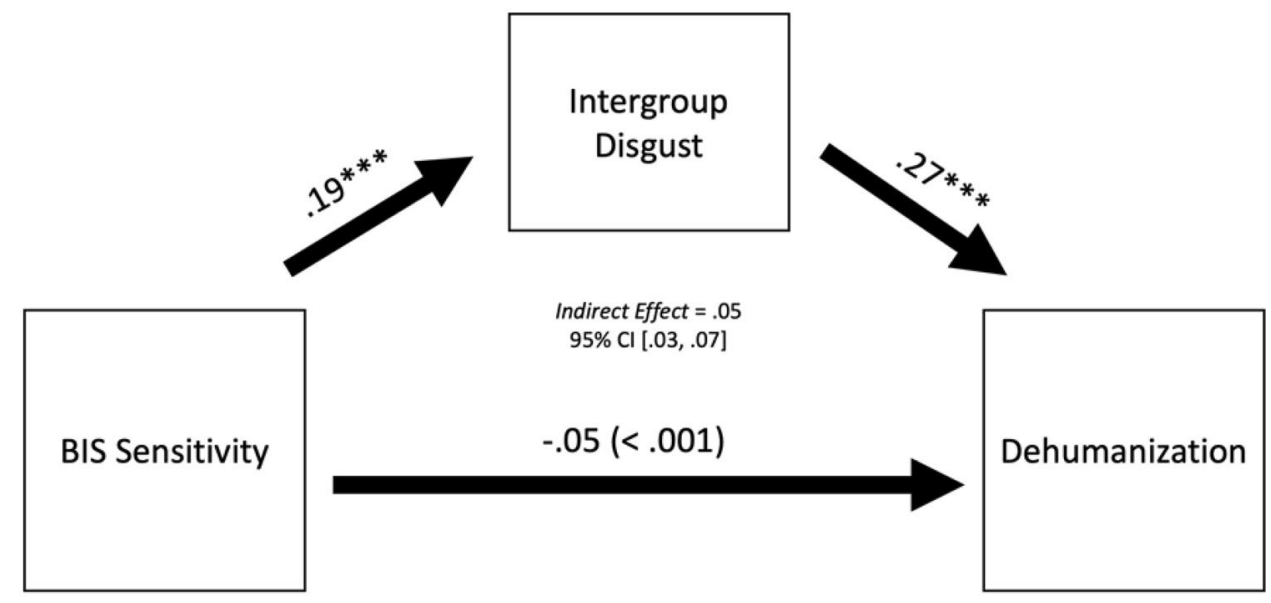

\section{Studies $\mathbf{2 a}$ and $\mathbf{2 b}$}

Because of the overwhelming costs of contracting a deadly infection, the BIS evolved to be overly sensitive to cues of potential disease, inspiring disgust toward targets even if they do not actually pose a threat of infection (Schaller, 2015). For instance, although in ancestral environments physical appearances deviating from the norm in terms of size and symmetry may have been a reliable cue the target was infected with a communicable pathogen (Kurzban \& Leary, 2001; Oaten et al., 2011), today people who are obese or have a facial disfigurement elicit disgust despite not posing any such threat (Park et al., 2007; Ryan et al., 2012). Similarly, in ancestral environments, foreign outgroups were likely to harbor novel pathogens that could be particularly virulent if introduced into one's own group (Schaller, 2015). Even if genetic cross-migration has now obviated this risk, cognitive predispositions to experience disgust toward subjectively foreign groups remain (Hodson et al., 2013). Thus, we sought to determine whether the Prophylactic Dehumanization Model generalized to Americans' dehumanization of groups with a deviant physical appearance (obese and disfigured people) and those with a subjectively foreign religion, nationality, or culture (Muslims, Somalis, and Mexican immigrants).

In addition, individuals who violate the ingroup's norms and traditions may arouse disgust because these cultural practices defend against contagion (e.g., sexual taboos; Schaller, 2015; Schaller \& Neuberg, 2012). ${ }^{8}$ Therefore, we also considered whether the BIS foments the dehumanization of outgroups thought to violate moral (homeless people, pedophiles, drug addicts) and sexual norms (homosexuals, transgender people). We anticipated a consistent trend in Americans' evaluations of these 10 social targets: their BIS sensitivity would predict greater disgust, which in turn would be associated with greater blatant dehumanization (Fig. 1). Moreover, to further determine the generality of our model, we introduced new measures of BIS sensitivity and dehumanization.

\section{Method}

\section{Participants}

On the basis of the effect size in study 1 , we conducted an a priori power analysis ( $G^{*}$ Power; Faul et al., 2007) and determined that 204 participants were required to detect a small-to-medium effect of intergroup disgust on dehumanization with $95 \%$ power. After excluding those who either failed multiple attention checks or were not American citizens (study 2a: $n=53$; study 2b: $n=43$ ), we were left with 234 participants in Study 2a (age: $M=35.43, S D=10.72$; 124 male, 109 female, 1 other) and 233 in study $2 b$ (age: $M=36.52, S D=13.02 ; 120$ male, 111 female, 2 other). A sensitivity analysis determined we had $95 \%$ power to detect an effect of $f^{2}=0.09$ in both studies ( $G^{*}$ Power; Faul et al., 2007).

\section{Materials}

Intergroup disgust, prejudice, SDO, and social conservatism were assessed as in study 1.

\footnotetext{
${ }^{8}$ However, others argue that disgust toward norm violators was shaped by selection pressures other than disease threats (e.g., Tybur et al., 2009). It is outside the scope of this research to weigh in conclusively on this debate, but we observed stronger relationships between BIS sensitivity and disgust toward groups with deviant appearances or a subjectively foreign nature $\left(r_{\mathrm{M}}=.53\right)$ and those perceived to violate sexual norms $\left(r_{\mathrm{M}}=.54\right)$ than toward moral norm violators $\left(r_{\mathrm{M}}=.30\right)$. Future research could systematically investigate whether the "domain" of disgust (pathogen, sexual, or moral; Tybur et al., 2009) influences the associations in our Prophylactic Dehumanization Model.
} 
BIS Sensitivity BIS sensitivity was measured with the 5-item contamination disgust subscale of the Disgust ScaleRevised (DS-R; Olatunji et al., 2007; study 2a: $a=0.73$; study $2 \mathrm{~b}: a=0.74)$, which measures fears about the transmission of pathogens (e.g., I never let any part of my body touch the toilet seat in a public washroom). Responses were made on a Likert scale ranging from 1 (Strongly disagree) to 7 (Strongly agree).

Images To heighten the visceral aversion characterizing intergroup disgust (Hodson et al., 2013), participants were presented with a set of images of each group as they evaluated them. The images were made publicly available online, and are available at https://osf.io/5387z/?view_ only $=61074 \mathrm{e} 103 \mathrm{~b} 2 \mathrm{e} 461 \mathrm{e} 958 \mathrm{~d} 62 \mathrm{f} 061193 \mathrm{e} 78$.

Dehumanization We assessed blatant dehumanization with a measure developed by Bastian et al. (2013). Participants rated the target group on 8 blatantly dehumanizing traits (e.g., Lacking self-restraint, like animals) using a scale that ranged from 1 (Not At All) to 7 (Extremely So). All $a \mathrm{~s} \geq 0.64$. $^{9}$

Demographics To ensure that participants were evaluating outgroup members, we included demographic items relevant to group membership and excluded participants who reported being in the group they were evaluating in our analyses. For instance, in study 2a we asked for participants' self-reported body weight on a Likert scale ranging from 1 (Very underweight) to 7 (Obese), and excluded all those who selected Obese when conducting analyses concerning that group $(n=7)$. In study $2 \mathrm{a}$, we also asked about participants' sexual orientation and religious affiliation, excluding those who responded Homosexual $(n=8)$ and Muslim $(n=5)$, respectively, in analyses concerning those groups. In study $2 \mathrm{~b}$, we excluded those who reported being transgender $(n=13)$, Somali $(n=6)$, or a Mexican immigrant $(n=14)$ in analyses concerning those respective groups. ${ }^{10}$

\section{Procedure}

The procedures for studies $2 \mathrm{a}$ and $2 \mathrm{~b}$ were identical except where stated otherwise. After providing consent, participants completed the contamination subscale to index their BIS sensitivity. They then completed the measures

\footnotetext{
${ }^{9}$ It should be noted that this measure is derived from the "Dual Model" of dehumanization (Haslam, 2006), which has recently been critiqued by Enock and colleagues (2021). Nonetheless, along with the Ascent of Man scale, this measure remains one of the few established measures of blatant dehumanization (see Kteily et al., 2015).

10 Patterns of significance remained unchanged when these individuals were retained in the analyses.
}

of intergroup disgust, blatant dehumanization, and prejudice, in that order. For each of these measures, participants evaluated five outgroups presented in randomized order. In study 2a, the groups were obese people, homosexuals, Muslims, child molesters, and homeless people. In study $2 b$, the groups were disfigured people, transgender people, Somalis, Mexican immigrants, and heroin addicts. Participants also rated their ingroup (Americans) on the measure of blatant dehumanization. Participants then completed measures of SDO, social conservatism, and provided demographic information. ${ }^{11}$

\section{Results and Discussion}

We conducted 10 simple mediations with the PROCESS macro (Model 4; Hayes, 2018), one for each outgroup. In each model, participants' BIS sensitivity was the predictor, their disgust toward a particular outgroup was the mediator, and their dehumanization of that group was the outcome. Their prejudice toward the outgroup, SDO, social conservatism, and ingroup dehumanization were entered as covariates. The descriptive statistics and intercorrelations for the variables in each model can be found in Tables S2-S11 of Online Resource 2, and path diagrams for each model can be found in Figs. S1-S10 of Online Resource 2.

Examining the $a$ path of each model, participants' BIS sensitivity strongly predicted their intergroup disgust ( $\beta \mathrm{s}$ ranged from 0.28 to 0.48 , all $p<0.001, \beta_{\mathrm{M}}=0.36$; see Table S12 in Online Resource 2). Intergroup disgust, in turn, was a strong predictor of dehumanization in 9 of the 10 models ( $b$ path; $\beta$ s ranged from 0.32 to 0.52 , all $p<0.001$, $\beta_{\mathrm{M}}=0.39$; see Table S13 in Online Resource 2). In 9 of the 10 models, we also observed a significant indirect effect of BIS sensitivity on dehumanization, mediated by disgust ( $\beta_{\text {indirect }}$ ranged from 0.11 to $0.18 ; \beta_{\text {indirect(M) }}=0.14$; Table 2 ). And pointing to the importance of intergroup disgust, when this variable was taken into account, BIS sensitivity exerted no significant effect on dehumanization in 7 of these 9 models, and actually reversed the direction of the effect in the other 2 (obese people and heroin addicts; both $\beta \mathrm{s}=-0.14$, $p<0.05){ }^{12}$

\footnotetext{
${ }^{11}$ Here and in study 3, participants completed additional measures for exploratory purposes which can be provided upon request.

${ }^{12}$ Zero-order correlations between BIS sensitivity and dehumanization were inconsistent, ranging from strong positive correlations between BIS sensitivity and the dehumanization of homosexuals and Muslims, to a moderate negative correlation between BIS sensitivity and the dehumanization of child molesters (see Tables S2-S11 in Online Resource 2).
} 
Table 2 Indirect effect of BIS sensitivity on dehumanization, mediated by intergroup disgust

\begin{tabular}{llll}
\hline Outgroup & Indirect effect & $95 \%$ CI & SE \\
\hline Obese people & .13 & {$[.07, .21]$} & .03 \\
Homosexuals & .17 & {$[.10, .24]$} & .03 \\
Muslims & .16 & {$[.10, .24]$} & .04 \\
Homeless people & .04 & {$[-.01, .12]$} & .03 \\
Child molesters & .14 & {$[.07, .22]$} & .04 \\
Disfigured people & .11 & {$[.05, .18]$} & .03 \\
Transgender people & .12 & {$[.06, .18]$} & .03 \\
Somalis & .14 & {$[.09, .21]$} & .03 \\
Mexican immigrants & .18 & {$[.10, .26]$} & .04 \\
Heroin addicts & .11 & {$[.04, .18]$} & .03 \\
\hline
\end{tabular}

SDO, social conservatism, prejudice toward the outgroup, and dehumanization of ingroup (Americans) were entered as covariates. Effects are standardized

The exception to this general pattern was the model concerning homeless people, in which participants' disgust did not predict dehumanization $(\beta=0.12, S E=0.05$, $t=1.75, p=0.082),{ }^{13}$ and there was no significant indirect effect of BIS sensitivity on dehumanization through disgust $\left(\beta_{\text {indirect }}=0.04, S E=0.03,95 \%\right.$ CI $\left.[-0.01,0.12]\right)$. Instead, general prejudice toward the homeless was the strongest predictor of their dehumanization, $\beta=0.48, S E=0.01, t=7.51$, $p<0.001$. In fact, general prejudice explained unique variance in dehumanization across all the models, while the other covariates (SDO and conservatism) emerged as less consistent predictors of dehumanization. ${ }^{14}$

Although this exception points to the need for future work to determine when intergroup disgust plays a greater or lesser role in dehumanization (see also Footnote 7), the overwhelming majority of results support the Prophylactic Dehumanization Model. Individuals with more sensitive behavioral immune systems were more prone to feel disgusted by outgroups stigmatized due to their deviant physical appearance, subjectively foreign nature, or violation of traditional norms. Intergroup disgust, in turn, strongly predicted dehumanization and fully mediated the effect of BIS sensitivity on dehumanization in the vast majority of the models. In fact, disgust frequently emerged as a stronger

\footnotetext{
13 Nonetheless, the zero-order correlation between disgust toward homeless people and dehumanization of them was $r=.44, p<.001$ (Table S5 in Online Resource 2).

${ }^{14}$ In 9 of the 10 models, general prejudice also explained unique variance in intergroup disgust (the exception was in the model concerning Muslims). And consistent with theories of disgust's hierarchymaintaining function (Rozin et al., 2008), SDO also explained unique variance in intergroup disgust across 9 of the 10 models (the exception was the model concerning child molesters). Social conservatism, on the other hand, was an inconsistent predictor of disgust across the models.
}

predictor of dehumanization than prejudice, SDO, and conservatism ( 7 of the 10 models). Nonetheless, the correlational nature of this study provides weak support for the causal assumptions underlying the model (Fig. 1). In study 3 , we sought firmer directional evidence by manipulating the salience of disease to determine whether it moderated the $B I S$ sensitivity $\rightarrow$ disgust $\rightarrow$ dehumanization pathway in a manner consistent with the functional flexibility of the BIS.

\section{Study 3}

The benefits of avoiding disease threats are at least partially offset by the costs of false alarms (e.g., missing an opportunity to establish a beneficial social relationship). This gives rise to functional flexibility in the BIS, where it exerts stronger effects on affect and behavior when the risk of infection is perceived to be greater (Schaller, 2015). For instance, the threat of disease strengthens the association between individuals' BIS sensitivity and their hostility to foreign immigrants (Aarøe et al., 2017). Therefore, we examined whether the threat of contracting COVID-19 strengthened the link between Americans' BIS sensitivity and their disgust toward foreign immigrants, and whether disgust in turn predicted dehumanization (Fig. 1). Given that dehumanization of immigrants foments support for punitive policies against them (Moore-Berg et al., 2021; Utych, 2018), we also tested whether our model of prophylactic dehumanization had a downstream effect on Americans' endorsement of punitive immigration policies and attitudes.

In sum, we hypothesized that individuals' BIS sensitivity would predict their anti-immigrant attitudes through (1) disgust toward and (2) dehumanization of immigrants. However, this was only expected to occur when the threat of COVID-19 was salient.

\section{Method}

\section{Participants}

On the basis of studies 1 and 2, we initially recruited 723 participants and excluded 149 who were not citizens, giving us a final sample of 574 (age: $M=36.79, S D=12.04 ; 295$ male, 273 female, 6 other). Using a tool for Monte Carlo post hoc power analysis (Schoemann et al., 2017), we determined that this sample gave us power of 0.93 to detect the serially mediated indirect effect we observed.

\section{Materials}

Intergroup disgust was measured as in previous studies and dehumanization was measured with the Ascent of Man scale (Kteily et al., 2015) as in study 1. 
Fig. 3 Effect of BIS sensitivity on anti-immigrant attitudes, mediated by disgust and dehumanization, and moderated by condition $(0=$ Control, $1=$ Pathogen Threat). The dashed lines indicate moderated pathways. The value above each dashed line shows the effect for those in the pathogen threat condition, while the italicized value below each line shows the effect for those in the control condition. Values reflect unstandardized coefficients. $* * * p<.001$

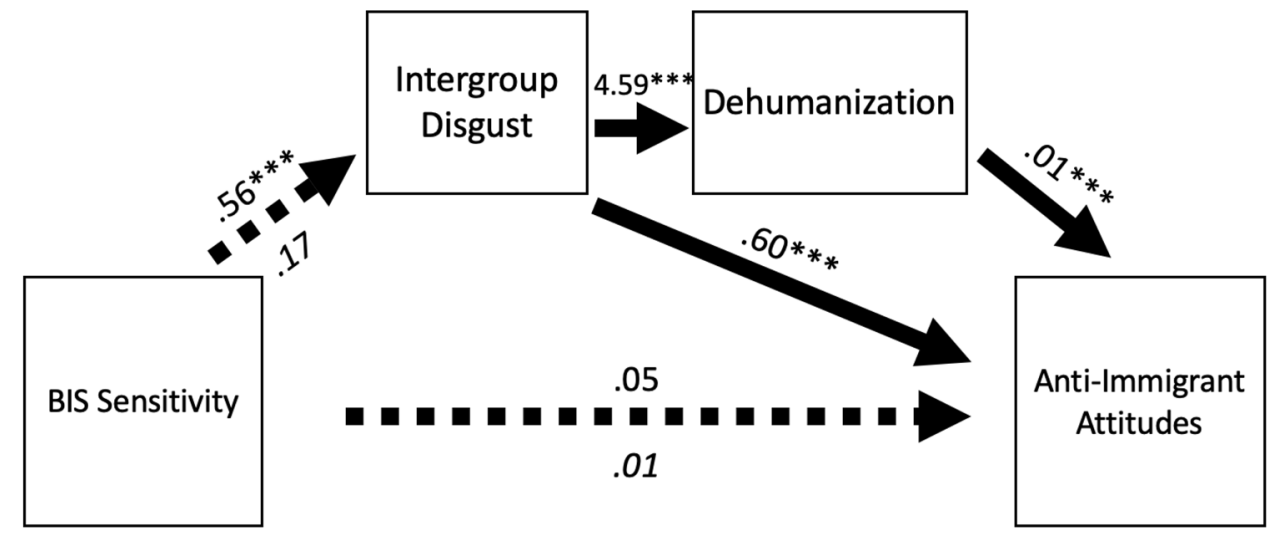

BIS Sensitivity Following Aarøe et al. (2017), we formed a robust index of BIS sensitivity with a composite measure consisting of the 7-item pathogen disgust subscale of the Three-Domain Disgust Scale (Tybur et al., 2009), on which participants rate their disgust toward infection risks such as Sitting next to someone who has red sores on their arm on a Likert scale ranging from 1 (Not at all disgusting) to 5 (Extremely disgusting), and the 8-item germ aversion subscale of the PVD scale used in study $1(a=0.76)$.

Anti-Immigrant Attitudes To assess anti-immigrant attitudes, we used a measure developed by Aarøe et al. $(a=0.86$; 2017). Participants rated their agreement with 6 items such as The government spends too much money assisting immigrants on a Likert scale ranging from 1 (Strongly Disagree) to 7 (Strongly Agree).

Manipulations We constructed two slideshows, one intended to make the threat of COVID-19 salient, and a control slideshow which made the danger of non-disease threats salient (see Faulkner et al., 2004 for precedent). Participants viewing the pathogen threat slideshow were told of different ways COVID-19 could be transmitted (person-to-person, airborne, surface, fecal-oral) and were presented with a list of symptoms related to the virus. Those viewing the control slideshow were told of non-disease threats to be aware of (e.g., water burns, poisoning, broken glass). Each slide had a short description and image accompanying it. These manipulations can be accessed at https://osf.io/5387z/?view_only= 61074e103b2e461e958d62f061193e78.

\section{Procedure}

After providing consent, all participants completed the germ aversion and pathogen disgust measures to index their BIS sensitivity. They were then randomly assigned to view the slideshow making either COVID-19 or non-disease threats salient. To reinforce the manipulation, participants were asked to Please select all the [ways you can contract the coronavirus/common accidents you should be aware of] from a dropdown list. All participants then completed the measure of anti-immigrant attitudes (items presented in randomized order) and evaluated both "citizens of your own country" and "foreign immigrants" (presented in counterbalanced order) on the Ascent measure of dehumanization. Finally, they reported their disgust toward foreign immigrants and provided demographics before being thoroughly debriefed.

\section{Results and Discussion}

To test our hypothesis that the effect of BIS sensitivity on anti-immigrant attitudes would be serially mediated by disgust and dehumanization, but only when COVID-19 was salient, we ran a custom moderated serial mediation using PROCESS (Hayes, 2018). ${ }^{15}$ BIS sensitivity was the predictor, disgust toward immigrants was the first mediator, dehumanization of them was the second mediator, and antiimmigrant attitudes was the outcome. We also included a direct path from disgust to anti-immigrant attitudes. A binary variable denoting experimental condition $(0=$ control, $1=$ pathogen threat) was created and entered as the moderator of the effect of BIS on disgust, as well as the direct effect of BIS on anti-immigrant attitudes. A path model is presented in Fig. 3, while descriptive statistics and intercorrelations among the continuous variables in the model are presented in Table 3. There were no significant differences between the experimental conditions on any of the variables.

We first examined the interaction between BIS sensitivity and experimental condition on disgust toward immigrants, $\Delta R^{2}=0.01, F(1,530)=5.47, p=0.02$. Consistent

\footnotetext{
15 Unlike in Studies 1 and 2, the effects report here are unstandardized because of the custom model we used.
} 
Table 3 Study 3 variable intercorrelations and descriptives

\begin{tabular}{|c|c|c|c|c|}
\hline Correlations & & 1 & 2 & 3 \\
\hline 1. BIS sensitivity & & - & & \\
\hline 2. Intergroup disgust & & $.18 * * *$ & - & \\
\hline 3. Dehumanization & & .03 & $.36 * * *$ & - \\
\hline 4. Anti-immigrant attitudes & & $.13 * *$ & $.71 * * *$ & $.35 * * *$ \\
\hline Descriptives & 1 & 2 & 3 & 4 \\
\hline$M$ & 4.83 & 3.04 & 17.92 & 3.43 \\
\hline$S D$ & 0.77 & 1.52 & 19.21 & 1.36 \\
\hline$\alpha$ & .76 & .90 & - & .86 \\
\hline
\end{tabular}

with the functional flexibility principle of the behavioral immune system, there was a significant effect of BIS sensitivity on disgust for those in the pathogen threat condition, $b=0.56, S E=0.12,95 \%$ CI [0.32, 0.79], $p<0.001$, but not for those in the control condition, $b=0.17, S E=0.12,95 \%$ CI $[-0.06,0.39], p=0.15$. We then examined the effect of BIS sensitivity on anti-immigrant attitudes, observing no significant direct effect in either condition (Fig. 3). However, disgust exerted a significant direct effect on antiimmigrant attitudes, $b=0.60, S E=0.03,95 \%$ CI [0.54, 0.66 , as did dehumanization, $b=0.01, S E=0.002,95 \%$ CI [0.004, 0.01].

We then examined the indirect path from BIS sensitivity to anti-immigrant attitudes, serially mediated by disgust and dehumanization. In the pathogen threat condition, the effect of BIS sensitivity on anti-immigrant attitudes was wholly mediated by disgust and dehumanization, $b_{\text {indirect }}=0.02, S E=0.01,95 \%$ CI $[0.01$, 0.04]. Conversely, in the control condition, there was no significant indirect path from BIS sensitivity to antiimmigrant attitudes, $b_{\text {indirect }}=0.01, S E=0.01,95 \%$ CI $[-0.002,0.02]$. Moreover, the index of moderated mediation was significant, $b=0.01, S E=0.01,95 \%$ CI [0.002, 0.03 ], indicating that BIS sensitivity was a significantly stronger predictor of anti-immigrant attitudes, through intergroup disgust and dehumanization, among those in the pathogen threat condition.

Thus, exposure to the threat of COVID-19 amplified the effect of the BIS on disgust toward foreign immigrants. Disgust, in turn, predicted greater dehumanization, consistent with the Prophylactic Dehumanization Model. Moreover, dehumanization had a downstream effect on anti-immigrant policies and attitudes, suggesting the pandemic's effect on xenophobic sentiments (e.g., Esses \& Hamilton, 2021) may in part be driven by the disgust and dehumanization arising from evolved predispositions to avoid disease.

\section{General Discussion}

Blatant dehumanization has inspired some of the darkest human atrocities and continues to foment racial discrimination, ethnic violence, and genocide (e.g., Bruneau \& Kteily, 2017; Goff et al., 2008; Smith, 2020). Despite reinvigorated scholarly interest in the construct (see Kteily \& Bruneau, 2017), insight into its psychological antecedents remains limited. We propose one driver of dehumanization lies in the disgust triggered by a hypersensitive behavioral immune system biased toward mitigating contact with outgroups (Fig. 1; Schaller, 2015). This is because disgust dampens empathy and mentalizing, two aspects integral to recognizing another's humanity (Hodson et al., 2014; Sherman \& Haidt, 2011).

We found substantial support for this Prophylactic Dehumanization Model. Individual differences in Americans' BIS sensitivity strongly predicted their disgust toward outgroups associated with the threat of COVID19 or probabilistically associated with disease cues in ancestral environments through their subjectively foreign nature, deviant physical appearance, or perceived violation ingroup norms. Moreover, the disgust felt toward these groups strongly predicted their dehumanization, over and above prejudice, SDO, and social conservatism, in 11 of the 12 cases we examined (and for the lone exception, homeless people, disgust and dehumanization had a strong zero-order correlation of $r=0.44, p<0.001)$. Importantly, intergroup disgust fully mediated the effect of BIS sensitivity on dehumanization across the vast majority of our models, and was also generally a stronger predictor of dehumanization than prejudice, SDO, and conservatism.

Study 3 provided two additional insights into this process. First, the link between BIS sensitivity and disgust was strengthened under conditions of pathogen threat, consistent with the functional flexibility of the BIS (Schaller, 2015). Second, the dehumanization of immigrants arising 
from this BIS-inspired disgust predicted greater antiimmigrant xenophobia, suggesting dehumanization is a key mediator of the well-documented relationship between BIS sensitivity and xenophobia. Indeed, likening immigrants to diseases foments anti-immigrant policy support (e.g., O'Brien, 2003; Utych, 2018), but encouragingly, interventions which reduce the dehumanization of immigrants can undermine such attitudes (Moore-Berg et al., 2021). We encourage future research to integrate our Prophylactic Dehumanization Model with intervention strategies reducing hostility to cultural and demographic change (e.g., Craig \& Richeson, 2014).

A better understanding of how evolved diseaseavoidance mechanisms contribute to dehumanization is crucial because disease-based genocidal ${ }^{16}$ rhetoric is by no means relegated to the past. As of this writing (June 30, 2021), 2-3 million Uyghurs have been subjected to indefinite internment in political "re-education" camps, mass surveillance, physical and psychological torture, and forced sterilization in Xinjiang, China (Associated Finnegan, 2020; Press, 2020; Smith Finley, 2020; Wang, 2018). During this time, Chinese media and political leaders have described the Uyghurs as infected with an "ideological virus" (i.e., a radical interpretation of Islam), necessitating a system of re-education "to cure ideological diseases" (Radio Free Asia, 2018; Ramzy \& Buckley, 2019; Wang, 2018). Such dehumanization is not isolated to radical outlets but also permeates official government mandates and discourse (China SCIO, 2019; Ramzy \& Buckley, 2019), leaving an indelible mark on many Uyghurs who experience it as eroding their dignity (Ala, 2021).

Unfortunately, our studies were conducted with low ecological validity (online self-report surveys) and a relatively homogenous participant pool (MTurk workers), thus limiting their generalizability to such instances of oppression where dehumanization is most problematic. Moreover, given the restrictions on human subject research during the pandemic, we were unable to investigate the BIS's effect on physical disgust responses or behavioral withdrawal (Schaller, 2015). Along with considering these outcomes, future work should also refine the role other emotions play in processes of dehumanization, such as anger and fear (Giner-Sorolla et al., 2019). Indeed, one may expect emotions other than disgust to play a crucial role in particular forms of dehumanization, such as fear in the association of Blacks with apes (Goff

\footnotetext{
16 Although the situation in Xinjiang is complex (e.g., the crackdown on the Uyghurs was, at least in part, inspired by genuine fears of terrorist violence on behalf of Uyghur radicals; Smith Finley, 2020) we side with the previous and current US Presidential administrations in labeling the practices of forced internment and sterilization in Xinjiang a cultural genocide (Hudson, 2021; Pamuk \& Brunnstrom, 2021).
}

et al., 2008). ${ }^{17} \mathrm{We}$ also encourage future research to build on our initial content analysis by investigating the prevalence of disease-based dehumanization in more comprehensive natural language corpora (see Mendelsohn et al., 2020).

The present research contributes to a reinvigorated scholarly interest in the blatant dehumanization which continues to mar contemporary conflicts (Kteily \& Bruneau, 2017). By identifying antecedents of dehumanization rooted in evolved prophylactic mechanisms, we provide a comprehensive framework for research into disease-based dehumanization (e.g., Valtorta et al., 2019, 2021) while advancing a broader stream of work documenting the impact of the BIS on intergroup relations (e.g., Aarøe et al., 2017; Faulkner et al., 2004). We encourage future efforts to refine the Prophylactic Dehumanization Model by considering behavioral outcomes, incorporating additional emotions, and employing ecologically valid approaches. Ultimately, we hope to inspire sustained inquiry into the psychological precursors of dehumanization in an effort to curb its corrosive influence on intergroup relations.

Supplementary Information The online version contains supplementary material available at https://doi.org/10.1007/s40806-021-00296-8.

Author Contribution A.L. developed the initial conceptualization, designed the studies, analyzed the data, and drafted the manuscript. E.I. assisted with data analysis and revisions to the manuscript, and J.S. provided revisions to the manuscript and general supervision.

Funding and Conflict of Interests This work was supported by the University of California, Santa Barbara (grant 3581). The authors have no relevant financial or non-financial interests to disclose.

Data Availability Data, syntax, and study materials can be found at https:// osf.io/5387z/?view_only=61074e103b2e461e958d62f061193e78.

\section{Declarations}

Ethical Approval The three studies reported in this manuscript received approval from the University of California, Santa Barbara's Institutional Review Board. Informed consent was obtained from all participants in each study.

Consent to participate Informed consent was obtained from all individual participants included in the study.

Consent for publication Participants consented to publishing the results with anonymous data.

\section{References}

Aarøe, L., Petersen, M. B., \& Arceneaux, K. (2017). The behavioral immune system shapes political intuitions: Why and how individual differences in disgust sensitivity underlie opposition to immigration. The American Political Science Review, 111(2), 277-294. https://doi.org/10.1017/S0003055416000770

\footnotetext{
$\overline{17}$ We credit an anonymous reviewer with this insight.
} 
Ala, M. (2021). Worse than death: Reflections on the Uyghur genocide. Hamilton Books.

AMJC. (2020). COVID-19 Roundup: Coronavirus Now a National Emergency, With Plans to Increase Testing. https://www.ajmc. com/view/covid19-roundup2

Associated Press. (2020). China cuts Uighur births with IUDs abortion sterilization. https://apnews.com/article/ap-top-news-international-newsweekend-reads-china-health-269b3de1af34e17c1941a514f78d764c

Bandura, A. (1999). Moral disengagement in the perpetration of inhumanities. Personality and Social Psychology Review, 3(3), 193 209. https://doi.org/10.1207/s15327957pspr0303_3

Bandura, A., Underwood, B., \& Fromson, M. E. (1975). Disinhibition of aggression through diffusion of responsibility and dehumanization of victims. Journal of Research in Personality, 9(4), 253-269.

Bastian, B., Denson, T. F., \& Haslam, N. (2013). The roles of dehumanization and moral outrage in retributive justice. PLOS ONE, 8(4), e61842. https://doi.org/10.1371/journal.pone.0061842

Brown, M., Keefer, L. A., Sacco, D. F., \& Bermond, A. (2019). Is the cure a wall? Behavioral immune system responses to a disease metaphor for immigration. Evolutionary Psychological Science, 5(3), 343-356. https://doi.org/10.1007/s40806-019-00191-3

Bruneau, E., \& Kteily, N. (2017). The enemy as animal: Symmetric dehumanization during asymmetric warfare. PLOS ONE, 12(7), e0181422. https://doi.org/10.1371/journal.pone.0181422

Buckels, E. E., \& Trapnell, P. D. (2013). Disgust facilitates outgroup dehumanization. Group Processes \& Intergroup Relations, 16(6), 771-780. https://doi.org/10.1177/1368430212471738

Bytwerk, R. L. (2012). Bending spines: The propagandas of Nazi Germany and the German Democratic Republic. MSU Press.

China SCIO. (2019). Vocational education and training in Xinjiang. http:// www.scio.gov.cn/zfbps/32832/Document/1662020/1662020.htm

Choma, B. L., Hodson, G., \& Costello, K. (2012). Intergroup disgust sensitivity as a predictor of islamophobia: The modulating effect of fear. Journal of Experimental Social Psychology, 48(2), 499506. https://doi.org/10.1016/j.jesp.2011.10.014

Choma, B. L., Haji, R., Hodson, G., \& Hoffarth, M. (2016). Avoiding cultural contamination: Intergroup disgust sensitivity and religious identification as predictors of interfaith threat, faith-based policies, and islamophobia. Personality and Individual Differences, 95, 50-55. https://doi.org/10.1016/j.paid.2016.02.013

Craig, M. A., \& Richeson, J. A. (2014). More diverse yet less tolerant? How the increasingly diverse racial landscape affects white Americans' racial attitudes. Personality and Social Psychology Bulletin, 40(6), 750-761. https://doi.org/10.1177/0146167214524993

Croucher, S. M., Nguyen, T., \& Rahmani, D. (2020). Prejudice toward Asian Americans in the COVID-19 pandemic: The effects of social media use in the United States. Frontiers in Communication, 5, 39. https://doi.org/10.3389/fcomm.2020.00039

Curtis, V., Aunger, R., \& Rabie, T. (2004). Evidence that disgust evolved to protect from risk of disease. Proceedings of the Royal Society of London Series b: Biological Sciences, 271, S131-S133. https://doi.org/10.1098/rsbl.2003.0144

Curtis, V., De Barra, M., \& Aunger, R. (2011). Disgust as an adaptive system for disease avoidance behaviour. Philosophical Transactions of the Royal Society b: Biological Sciences, 366(1563), 389-401. https://doi.org/10.1098/rstb.2010.0117

Dalsklev, M., \& Kunst, J. R. (2015). The effect of disgust-eliciting media portrayals on outgroup dehumanization and support of deportation in a Norwegian sample. International Journal of Intercultural Relations, 47, 28-40. https://doi.org/10.1016/j.ijintrel.2015.03.028

Darling-Hammond, S., Michaels, E. K., Allen, A. M., Chae, D. H., Thomas, M. D., Nguyen, T. T., \& Johnson, R. C. (2020). After "The China Virus" went viral: Racially charged coronavirus coverage and trends in bias against Asian Americans. Health Education \& Behavior. https://doi.org/10.1177/1090198120957949
Diamond, J. (1997). Guns germs and steel: The fates of human societies. Vintage.

Duncan, L. A., Schaller, M., \& Park, J. H. (2009). Perceived vulnerability to disease: Development and validation of a 15-item self-report instrument. Personality and Individual Differences, 47(6), 541-546. https://doi.org/10.1016/j.paid.2009.05.001

Enock, F., Tipper, S., \& Over, H. (2020). No convincing evidence that outgroup members are dehumanised: Revisiting trait and emotion attribution in intergroup bias. https://psyarxiv.com/ hm82y/

Enock, F. E., Flavell, J. C., Tipper, S. P., \& Over, H. (2021). No convincing evidence outgroups are denied uniquely human characteristics: Distinguishing intergroup preference from trait-based dehumanization. Cognition, 212, 104682. https://doi.org/10. 1016/j.cognition.2021.104682

Esses, V. M., \& Hamilton, L. K. (2021). Xenophobia and anti-immigrant attitudes in the time of COVID-19. Group Processes \& Intergroup Relations, 24(2), 253-259. https://doi.org/10.1177/ 1368430220983470

Faul, F., Erdfelder, E., Lang, A. G., \& Buchner, A. (2007). G* Power 3: A flexible statistical power analysis program for the social, behavioral, and biomedical sciences. Behavior Research Methods, 39(2), 175-191. https://doi.org/10.3758/BF03193146

Faulkner, J., Schaller, M., Park, J. H., \& Duncan, L. A. (2004). Evolved disease-avoidance mechanisms and contemporary xenophobic attitudes. Group Processes \& Intergroup Relations, 7(4), 333-353. https://doi.org/10.1177/1368430204046142

Fincher, K. M., Kteily, N. S., \& Bruneau, E. G. (2018). Our humanity contains multitudes: Dehumanization is more than overlooking mental capacities. Proceedings of the National Academy of Sciences, 115(15), E3329-E3330. https://doi.org/10.1073/pnas. 1800359115

Finnegan, C. (2020). The Uyghur minority in China: A case study of cultural genocide, minority rights and the insufficiency of the International legal framework in preventing state-imposed extinction. Laws, 9(1), 1. https://doi.org/10.3390/laws9010001

Giner-Sorolla, R., Russell, P. S., Vazire, S., \& Inbar, Y. (2019). Not just disgust: Fear and anger also relate to intergroup dehumanization. Collabra: Psychology, 5(1). https://doi.org/10.1525/collabra.211

Goff, P. A., Eberhardt, J. L., Williams, M. J., \& Jackson, M. C. (2008). Not yet human: Implicit knowledge, historical dehumanization, and contemporary consequences. Journal of Personality and Social Psychology, 94(2), 292-306. https://doi.org/10.1037/00223514.94.2.292

Haddock, G., Zanna, M. P., \& Esses, V. M. (1993). Assessing the structure of prejudicial attitudes: The case of attitudes toward homosexuals. Journal of Personality and Social Psychology, 65(6), 1105-1118. https://doi.org/10.1037/0022-3514.65.6.1105

Harris, L. T., \& Fiske, S. T. (2011). Dehumanized perception: A psychological means to facilitate atrocities, torture, and genocide? Zeitschrift Für Psychologie, 219(3), 175-181. https://doi.org/10. 1027/2151-2604/a000065

Haslam, N. (2006). Dehumanization: An integrative review. Personality and Social Psychology Review, 10(3), 252-264. https://doi.org/10. 1207/s15327957pspr1003_4

Hayes, A. F. (2018). Introduction to mediation moderation and conditional process analysis: A regression-based approach. Guilford Press.

Ho, A. K., Sidanius, J., Kteily, N., Sheehy-Skeffington, J., Pratto, F., Henkel, K. E., Foels, R., \& Stewart, A. L. (2015). The nature of social dominance orientation: Theorizing and measuring preferences for intergroup inequality using the new SDO7 scale. Journal of Personality and Social Psychology, 109(6), 1003-1028. https:// doi.org/10.1037/pspi0000033

Hodson, G., \& Costello, K. (2007). Interpersonal disgust, ideological orientations, and dehumanization as predictors of intergroup 
attitudes. Psychological Science, 18(8), 691-698. https://doi.org/ 10.1111/j.1467-9280.2007.01962.x

Hodson, G., Choma, B. L., Boisvert, J., Hafer, C. L., MacInnis, C. C., \& Costello, K. (2013). The role of intergroup disgust in predicting negative outgroup evaluations. Journal of Experimental Social Psychology, 49(2), 195-205. https://doi.org/10.1016/j.jesp.2012. 11.002

Hodson, G., Kteily, N., \& Hoffarth, M. (2014). Of filthy pigs and subhuman mongrels: Dehumanization, disgust, and intergroup prejudice. TPM: Testing, Psychometrics, Methodology in Applied Psychology, 21(3).

Hudson, J. (2021). In report, Biden administration formalizes genocide declaration in China. The Seattle Times. https://www.seattletimes. $\mathrm{com} /$ nation-world/in-report-biden-administration-formalizesgenocide-declaration-in-china/

Kteily, N. S., \& Bruneau, E. (2017). Darker demons of our nature: The need to (re) focus attention on blatant forms of dehumanization. Current Directions in Psychological Science, 26(6), 487-494. https://doi.org/10.1177/0963721417708230

Kteily, N., Bruneau, E., Waytz, A., \& Cotterill, S. (2015). The ascent of man: Theoretical and empirical evidence for blatant dehumanization. Journal of Personality and Social Psychology, 109(5), 901-931. https://doi.org/10.1037/pspp0000048

Kurzban, R., \& Leary, M. R. (2001). Evolutionary origins of stigmatization: The functions of social exclusion. Psychological Bulletin, 127(2), 187-208. https://doi.org/10.1037/0033-2909.127.2.187

Landry, A. P., Ihm, E., \& Schooler, J. W. (2021). Hated but still human: Metadehumanization leads to greater hostility than metaprejudice. Group Processes \& Intergroup Relations, 1368430220979035 , 1-20. https://doi.org/10.1177/1368430220979035

Lang, J. (2010). Questioning dehumanization: Intersubjective dimensions of violence in the Nazi concentration and death camps. Holocaust and Genocide Studies, 24(2), 225-246. https://doi. org/10.1093/hgs/dcq026

Luft, A. (2019). Dehumanization and the normalization of violence: It's not what you think. Social Science Research Council. https:// items.ssrc.org/insights/dehumanization-and-the-normalization-ofviolence-its-not-what-you-think/

Maoz, I., \& McCauley, C. (2008). Threat, dehumanization, and support for retaliatory aggressive policies in asymmetric conflict. Journal of Conflict Resolution, 52(1), 93-116. https://doi.org/10.1177/ 0022002707308597

Markowitz, D. M., Shoots-Reinhard, B., Peters, E., Silverstein, M. C., Goodwin, R., \& Bjälkebring, P. (2021). Dehumanization during the COVID-19 pandemic. Frontiers in Psychology, 12, 285. https://doi.org/10.3389/fpsyg.2021.634543

Mendelsohn, J., Tsvetkov, Y., \& Jurafsky, D. (2020). A framework for the computational linguistic analysis of dehumanization. Frontiers in Artificial Intelligence, 3, 55. https://doi.org/10.3389/frai. 2020.00055

Moore-Berg, S. L., Hameiri, B., \& Bruneau, E. G. (2021). Empathy,dehumanization, and misperceptions: A media intervention humanizes migrants andincreases empathy for their plight but only if misinformation about migrants isalso corrected. Social Psychological and Personality Science, 19485506211012793. https:// doi.org/10.1177/19485506211012793

Musolff, A. (2007). What role do metaphors play in racial prejudice? The function of antisemitic imagery in Hitler's Mein Kampf. Patterns of Prejudice, 41(1), 21-43. https://doi.org/10.1080/00313 220601118744

Navarrete, C. D., Fessler, D. M., \& Eng, S. J. (2007). Elevated ethnocentrism in the first trimester of pregnancy. Evolution and Human Behavior, 28(1), 60-65. https://doi.org/10.1016/j.evolhumbehav. 2006.06.002

Neilsen, R. S. (2015). 'Toxification' as a more precise early warning sign for genocide than dehumanization? An emerging research agenda. Genocide Studies and Prevention: An International Journal, 9(1), 93-95. https://doi.org/10.5038/1911-9933.9.1.1277

Oaten, M., Stevenson, R. J., \& Case, T. I. (2011). Disease avoidance as a functional basis for stigmatization. Philosophical Transactions of the Royal Society b: Biological Sciences, 366(1583), 3433-3452. https://doi.org/10.1098/rstb.2011.0095

O'Brien, G. V. (2003). Indigestible food, conquering hordes, and waste materials: Metaphors of immigrants and the early immigration restriction debate in the United States. Metaphor and Symbol, 18(1), 33-47. https://doi.org/10.1207/S15327868MS1801_3

Olatunji, B. O., Williams, N. L., Tolin, D. F., Abramowitz, J. S., Sawchuk, C. N., Lohr, J. M., \& Elwood, L. S. (2007). The Disgust Scale: Item analysis, factor structure, and suggestions for refinement. Psychological Assessment, 19(3), 281-297. https://doi.org/10.1037/10403590.19.3.281

Over, H. (2021). Seven challenges for the dehumanization hypothesis. Perspectives on Psychological Science, 16(1), 3-13. https://doi.org/ $10.1177 / 1745691620902133$

Pamuk, H., \& Brunnstrom, D. (2021). In parting shot, Trump administration accuses China of 'genocide' against Uighurs. Reuters. https:// www.reuters.com/article/us-usa-china-genocide/in-parting-shottrump-administration-accuses-china-of-genocide-against-uighursidUSKBN29O25F

Park, J. H., Schaller, M., \& Crandall, C. S. (2007). Pathogen-avoidance mechanisms and the stigmatization of obese people. Evolution and Human Behavior, 28(6), 410-414. https://doi.org/10.1016/j. evolhumbehav.2007.05.008

Pratto, F., Sidanius, J., Stallworth, L. M., \& Malle, B. F. (1994). Social dominance orientation: A personality variable predicting social and political attitudes. Journal of Personality and Social Psychology, 67(4), 741-763. https://doi.org/10.1037/0022-3514.67.4.741

Radio Free Asia. (2018). Xinjiang political 're-education camps' treat Uyghurs 'infected by religious extremism': CCP Youth League. https://www.rfa.org/english/news/uyghur/infected-08082018173807. html

Rai, T. S., Valdesolo, P., \& Graham, J. (2017). Dehumanization increases instrumental violence, but not moral violence. Proceedings of the National Academy of Sciences, 114(32), 8511-8516. https://doi.org/10.1073/pnas.1705238114

Ramzy, A., \& Buckley, C. (2019). 'Absolutely no mercy': Leaked files expose how China organized mass detentions of Muslims. The New York Times. https://www.nytimes.com/interactive/2019/11/ 16/world/asia/china-xinjiang-documents.html

Ren, S. Y., Gao, R. D., \& Chen, Y. L. (2020). Fear can be more harmful than the severe acute respiratory syndrome coronavirus 2 in controlling the corona virus disease 2019 epidemic. World journal of clinical cases, 8(4), 652-657. https://doi.org/10.12998/wjcc.v8.i4.652

Rozin, P., Haidt, J., \& McCauley, C. R. (2008). Disgust. In M. Lewis, J. M. Haviland-Jones, \& L. F. Barrett (Eds.), Handbook of emotions (pp. 757-776). The Guilford Press.

Ryan, S., Oaten, M., Stevenson, R. J., \& Case, T. I. (2012). Facial disfigurement is treated like an infectious disease. Evolution and Human Behavior, 33(6), 639-646. https://doi.org/10.1016/j.evolhumbehav. 2012.04.001

Savage, R. (2007). "Disease incarnate": Biopolitical discourse and genocidal dehumanisation in the age of modernity. Journal of Historical Sociology, 20(3), 404-440. https://doi.org/10.1111/j. 1467-6443.2007.00315.x

Schaller, M. (2015). The behavioral immune system. The handbook ofevolutionary psychology, 1-19. https://doi.org/10.1002/ 9781119125563.evpsych107

Schaller, M., \& Duncan, L. A. (2007). The behavioral immune system: Its evolution and social psychological implications. In J. P. Forgas, M. G. Haselton, \& W. von Hippel (Eds.), Evolution and the social mind: Evolutionary psychology and social cognition (p. 293-307). Routledge/Taylor \& Francis Group. 
Schaller, M., \& Neuberg, S. L. (2012). Danger, disease, and the nature of prejudice(s). In Advances in experimental social psychology (Vol. 46, pp. 1-54). Academic Press.

Schoemann, A. M., Boulton, A. J., \& Short, S. D. (2017). Determining power and sample size for simple and complex mediation models. Social Psychological and Personality Science, 8(4), 379-386. https://doi.org/10.1177/1948550617715068

Sherman, G. D., \& Haidt, J. (2011). Cuteness and disgust: The humanizing and dehumanizing effects of emotion. Emotion Review, 3(3), 245-251. https://doi.org/10.1177/1754073911402396

Skinner, A. L., \& Hudac, C. M. (2017). "Yuck, you disgust me!" Affective bias against interracial couples. Journal of Experimental Social Psychology, 68, 68-77. https://doi.org/10.1016/j.jesp. 2016.05.008

Smith, D. L. (2020). On inhumanity: Dehumanization and how to resist it. Oxford University Press.

Smith Finley, J. (2020). Why scholars and activists increasingly fear aUyghur genocide in Xinjiang. Journal of Genocide Research, 1-23. https://doi.org/10.1080/14623528.2020.1848109

Tavernese, S., \& Oppel Jr., R. A. (2020). Spit on, yelled at, attacked: Chinese-Americans fear for their safety. The New York Times. https://www.nytimes.com/2020/03/23/us/chinese-coronavirusracist-attacks.html

Terrizzi, J. A., Jr., Shook, N. J., \& Ventis, W. L. (2010). Disgust: A predictor of social conservatism and prejudicial attitudes toward homosexuals. Personality and Individual Differences, 49(6), 587592. https://doi.org/10.1016/j.paid.2010.05.024

Tybur, J. M., Lieberman, D., \& Griskevicius, V. (2009). Microbes, mating, and morality: Individual differences in three functional domains of disgust. Journal of Personality and Social Psychology, 97(1), 103-122. https://doi.org/10.1037/a0015474
Utych, S. M. (2018). How dehumanization influences attitudes toward immigrants. Political Research Quarterly, 71(2), 440-452. https:// doi.org/10.1177/1065912917744897

Valtorta, R. R., Baldissarri, C., Andrighetto, L., \& Volpato, C. (2019), The dirty side of work: Biologization of physically tainted workers. International Review of Social Psychology, 32(1), 1-13. https://doi.org/10.5334/irsp.213

Valtorta, R. R., Baldissarri, C., Andrighetto, L., \& Volpato, C. (2021). Seeing others as a disease: The impact of physical (but not moral) disgust on biologization. International Review of Social Psychology, 34(1). https://doi.org/10.5334/irsp.407

Viki, G. T., Osgood, D., \& Phillips, S. (2013). Dehumanization and self-reported proclivity to torture prisoners of war. Journal of Experimental Social Psychology, 49(3), 325-328. https://doi.org/ 10.1016/j.jesp.2012.11.006

Wang, M. (2018). "Eradicating ideological viruses": China's campaign of repression against Xinjiang's Muslims. Human Rights Watch. https://www.hrw.org/report/2018/09/09/eradicating-ideologicalviruses/chinas-campaign-repression-against-xinjiangs\#7796

Waśniewska, M. (2017). The socio-parasite and bio-parasite metaphorical concepts in racist discourse. Crossroads A Journal of English Studies, 2(17), 46-61. https://doi.org/10.15290/cr.2017.17.2.03

Zhai, Y., \& Du, X. (2020). Mental health care for international Chinese students affected by the COVID-19 outbreak. The Lancet Psychiatry, 7(4), e22. https://doi.org/10.1016/S2215-0366(20)30089-4

Publisher's Note Springer Nature remains neutral with regard to jurisdictional claims in published maps and institutional affiliations. 